\title{
Bioelectronic tongue based on lipidic nanostructured layers containing phenol oxidases and lutetium bisphthalocyanine for the analysis of grapes
}

\author{
C. Medina-Plaza ${ }^{\text {a }}$ J.A. de Saja ${ }^{\text {b }}$, M.L. Rodriguez-Mendez ${ }^{\text {a,* }}$ \\ a Department of Inorganic Chemistry, Engineers School, Universidad de Valladolid, 47011 Valladolid, Spain \\ ${ }^{\mathrm{b}}$ Department of Condensed Matter Physics, Faculty of Sciences, Universidad de Valladolid, 47011 Valladolid, Spain
}

\section{A R T I C L E I N F O}

\section{Article history:}

Received 17 October 2013

Received in revised form

22 January 2014

Accepted 10 February 2014

Available online 19 February 2014

\section{Keywords:}

Electronic tongue

Bisphthalocyanine

Phenol

Voltammetric sensor

Tyrosinase

Laccase

\begin{abstract}
A B S T R A C T
In this work, a multisensor system formed by nanostructured voltammetric biosensors based on phenol oxidases (tyrosinase and laccase) has been developed. The enzymes have been incorporated into a biomimetic environment provided by a Langmuir-Blodgett (LB) film of arachidic acid (AA). Lutetium bisphthalocyanine $\left(\mathrm{LuPC}_{2}\right)$ has also been introduced in the films to act as electron mediator. The incorporation of the enzymes to the floating layers to form Tyr/AA/LuPc $c_{2}$ and $\mathrm{Lac} / \mathrm{AA} / \mathrm{LuPc}_{2}$ films has been confirmed by the expansion in the surface pressure isotherms and by the AFM images. The voltammetric response towards six phenolic compounds demonstrates the enhanced performance of the biosensors that resulted from a preserved activity of the tyrosinase and laccase combined with the electron transfer activity of $\mathrm{LuPc}_{2}$. Biosensors show improved detection limits in the range of $10^{-7}$ $10^{-8} \mathrm{~mol} \mathrm{~L}^{-1}$. An array formed by three sensors $\mathrm{AA} / \mathrm{LuPc}_{2}, \mathrm{Tyr} / \mathrm{AA} / \mathrm{LuPc}_{2}$ and $\mathrm{Lac} / \mathrm{AA} / \mathrm{LuPc}_{2}$ has been employed to discriminate phenolic antioxidants of interest in the food industry. The Principal Component Analysis scores plot has demonstrated that the multisensor system is able to discriminate phenols according to the number of phenolic groups attached to the structure. The system has also been able to discriminate grapes of different varieties according to their phenolic content. This good performance is due to the combination of four factors: the high functionality of the enzyme obtained using a biomimetic immobilization, the signal enhancement caused by the $\mathrm{LuPc}_{2}$ mediator, the improvement in the selectivity induced by the enzymes and the complementary activity of the enzymatic sensors demonstrated in the loading plots.
\end{abstract}

(c) 2014 Elsevier B.V. All rights reserved.

\section{Introduction}

The determination of phenols, the main antioxidants in foods, has been widely investigated using traditional techniques including spectroscopy, chromatography and electrochemical methods (Mello et al., 2010; Bartosz, 2013).

A promising approach in food analysis consists in the use of electronic tongues which are multisensor systems based on a number of low-selective sensors and use advanced mathematical procedures for processing the electrochemical signals, based on pattern recognition and/or multivariate data analysis (Vlasov et al., 2005; Tahara and Toko, 2013). Electronic tongues provide global

\footnotetext{
* Correspondence to: Department of Inorganic Chemistry, Escuela de Ingenierías Industriales, Paseo del Cauce, 59, 47011 Valladolid. Spain. Tel.: + 3498342 3540; fax: + 34983423310

E-mail address: mluz@eii.uva.es (M.L. Rodriguez-Mendez).
}

information about the sample instead of information about specific compounds.

Electrochemical sensors are the most widely used sensing units in electronic tongues. They include potentiometric (Ciosek and Wroblewski, 2011), amperometric (Scampicchio et al., 2008), voltammetric (Winquist et al., 2011; Escobar et al., 2013; Rodriguez-Mendez et al., 2008) or impedimetric sensors (Cabral et al., 2009).

Arrays of voltammetric electrodes chemically modified with electroactive materials (i.e. phthalocyanines) have demonstrated to be particularly interesting for the analysis of phenolic compounds (Gay et al., 2012; Ceto et al., 2012a; Parra et al., 2006). When using such electrodes, voltammograms show redox peaks produced by the electrode material and by the solution. In addition, the interactions between the electrode and the solution (i.e. electrocatalytic activity of the sensing material) produce shifts in the peak positions and changes in their intensity. In this way, each electrode produces a distinct response towards different solutions. The intrinsic complexity, richness and cross-selectivity 
of the signals generated by an array of voltammetric electrodes are an advantage because each curve contains large amount of information about the sample (Rodriguez-Mendez et al., 2008; Winquist et al., 2011).

Phthalocyanines (MPc) and their sandwich type lanthanide derivatives $\left(\mathrm{LnPc}_{2}\right)$ are among the most suitable materials for electrochemical sensors due to their well-known electrocatalytic properties (Zagal et al., 2010; Bouvet et al., 2013; RodriguezMendez et al., 2008). They have demonstrated to behave as excellent modifiers for the detection of a variety of analytes including polyphenolic compounds (Gay et al., 2012; Ceto et al., 2012a; Matemadombo et al., 2012). Nanostructured electrochemical sensors based on phthalocyanines can be prepared using the Langmuir-Blodgett (LB) technique (Arrieta et al., 2003; Volpati et al., 2008).

On the other hand, electrochemical biosensors are an interesting alternative for the analysis of phenols due their high sensitivity and selectivity. They contain phenol oxidase enzymes such as tyrosinase or laccase combined with appropriate electron mediators such as metallic nanoparticles, graphene and conducting polymers among others (Karim and Fakhruddin, 2012). It has been demonstrated that MPcs and $\mathrm{LnPc}_{2}$ can also be used as electron mediators in tyrosinase biosensors (Yin et al., 2010; Fernandes et al., 2011; Apetrei et al., 2011). The LB technique is of special interest in the field of biosensors because using this method enzymes can be immobilized in a nanostructured lipidic layer with a structure similar to that of the biological membranes. This biomimetic environment can help to preserve the functionality of the enzyme (Soloducho et al., 2009; Fernandes et al., 2011; Apetrei et al., 2011). In addition, using the LB technique, the enzyme and the electron mediator can be co-inmobilized in a single sensitive layer, facilitating the electron transfer between the enzyme and the electrode.

Some attempts have been carried out to develop arrays of biosensors containing phenol oxidases for the detection of phenols (the so-called bioelectronics tongues) (Ceto et al., 2012b; GhasemiVarnamkhasti et al., 2012). It has been demonstrated that arrays of biosensors combine the advantages of classical arrays of electrochemical sensors that provide global information about the sample, with the specificity of the enzyme-substrate reaction typical of biosensors. However, in these previous works only non-nanostructured sensors have been used.

The purpose of this work is to develop a bioelectronic tongue based on an array of nanostructured biosensors combining the sensing properties of two different phenol oxidases-tyrosinase and laccase-, and to evaluate its capability of discrimination towards phenols of interest in the food industry. The enzymes have been incorporated into LB films of arachidic acid using lutetium bisphthalocyanine as the electron mediator. Cyclic voltammetry has been applied to detect six phenolic compounds including one monophenol, three orto-diphenols and two triphenols. The complementarity achieved by the different sensors and the electron mediator capability of the bisphthalocyanine will be discussed.

\section{Materials and methods}

\subsection{Chemicals}

All chemical and solvents were of reagent grade. Deionized water (resistivity of $18.2 \mathrm{M} \Omega \mathrm{cm}^{-1}$ ) was used to prepare subphases and solutions.

Laccase, from Trametes versicolor (EC number: 1.10.3.2, activity of $20.7 \mathrm{U} \mathrm{mg}^{-1}$ ) and Tyrosinase (from mushroom EC 232-653-4), noted activity of $3610 \mathrm{U} \mathrm{mg}^{-1}$ were purchased from Sigma
Chemical. $70 \mu \mathrm{g} \mathrm{mL}^{-1}$ solutions of tyrosinase and laccase were prepared in buffer phosphate $0.01 \mathrm{~mol} \mathrm{~L}^{-1}(\mathrm{pH}=7.0)(\mathrm{PBS})$.

The lutetium (III) bisphthalocyaninate $\left(\mathrm{LuPc}_{2}\right)$ was synthesized following a previously published procedure (Linaje et al., 2000).

\subsection{Langmuir and Langmuir-Blodgett films}

Isotherms and LB films were prepared in a KSV 5000 Langmuir-Blodgett trough (KSV Instruments, Finland) equipped with a Wilhelmy plate to measure the surface pressure.

According to a previously published method, LB films were prepared using a PBS- $\mathrm{NaCl}$ subphase $(\mathrm{NaCl} 0.1 \mathrm{M}$, phosphate buffer $0.01 \mathrm{M}$ of $\mathrm{pH}=7.0$ in ultrapure water) (Apetrei et al., 2011).

Mixed films containing arachidic acid (AA) and lutetium bisphthalocyanine $\left(\mathrm{LuPc}_{2}\right)$ were prepared by spreading $250 \mu \mathrm{l}$ of a mixture 10:1 $\left(\mathrm{AA} / \mathrm{LuPc}_{2}\right)$ dissolved in chloroform $\left(1 \times 10^{-5} \mathrm{~mol} \mathrm{~L}^{-1}\right)$ onto the PBS-NaCl subphase. The surfacearea isotherms were measured by compressing the floating molecules at a speed of $10 \mathrm{~mm} \mathrm{~min}^{-1}$.

At a surface pressure of $40 \mathrm{mN} \mathrm{m}^{-1}, 20$ monolayers were deposited onto previously cleaned ITO glass surface, by Y-type deposition with a transfer ratio close to 1 .

LB films containing enzyme, arachidic acid and lutetium bisphthalocyanine (Enz/AA/LuPc $)$, were prepared in two steps. First, 10 monolayers of $\mathrm{AA} / \mathrm{LuPc}_{2}$ were deposited using the method described in the previous paragraphs. Then, 10 monolayers of Enz/ $\mathrm{AA} / \mathrm{LuPc}_{2}$ were deposited onto the $\mathrm{AA} / \mathrm{LuPc}_{2}$ layers as follows: $250 \mu \mathrm{l}$ of the $\mathrm{AA} / \mathrm{LuPc}_{2}$ solution were spread onto the PBS-NaCl subphase. When the solvent was evaporated, $100 \mu \mathrm{l}$ of a $70 \mu \mathrm{g} \mathrm{ml}^{-1}$ solution of the corresponding enzyme in $0.01 \mathrm{~mol} \mathrm{~L}^{-1}$ PBS were injected drop by drop underneath the air/liquid interface. Barriers were compressed at a speed of $10 \mathrm{~mm} \mathrm{~min}^{-1}$. At a surface pressure of $40 \mathrm{mN} \mathrm{m}^{-1}, 10$ monolayers of Enz/AA/LuPc 2 were deposited onto ITO glass with a substrate speed of $3 \mathrm{~mm} \mathrm{~min}{ }^{-1}$. Films were built by $\mathrm{Y}$ type deposition with a transfer ratio close to 1 .

After preparation, LB films of Enz/AA/LuPc 2 were treated with glutharaldehyde to form covalent bonds between the enzymes and the amphiphilic molecules (Pavinatto et al., 2011).

Langmuir films were analyzed with Brewster Angle Microscopy (BAM) using a KSV MicroBAM.

AFM images were registered in LB films deposited onto ITO using a MultiMode Scanning Probe Microscope Model MMAFM-2 from Digital Instruments.

\subsection{Electrochemical measurements}

The electrochemical measurements were carried out in an EG\&G PARSTAT 2273 potentiostat/galvanostat using a conventional three-electrode cell. The LB films were used as the working electrode. The reference electrode was $\mathrm{Ag} / \mathrm{AgCl} / \mathrm{KCl} 3 \mathrm{~mol} \mathrm{~L}^{-1}$ and the counter electrode was a platinum plate. Cyclic voltammograms were registered at a sweep rate of $0.1 \mathrm{~V} \mathrm{~s}^{-1}$.

\subsection{Phenols and grapes}

$10^{-3} \mathrm{~mol} \mathrm{~L}^{-1}$ stock solutions of phenolic compounds including one monophenol (vanillic acid), two orto-diphenols (catechol and caffeic acid), one para-diphenol (hydroquinone) and two triphenols (gallic acid and pyrogallol) were prepared by solving the corresponding compound in PBS. Solutions with lower concentration were prepared by dilution.

Grapes of five different varieties (Tempranillo, Garnacha, Cabernet, Prieto Picudo and Mencía) were harvested in 2012 in the Castilla y León region (Spain) by the Agrotechnological Institute of the regional Government (ITACYL), and by a cellar of the region 
(Bodega Cooperativa de Cigales). The Enological Centre of Castilla y León carried out the chemical analysis including the Total Polyphenol Index (TPI) following international regulations (OIV, 2013).

\subsection{Statistical analysis. Data treatment}

A non-supervised multivariate method, the Principal Component Analysis (PCA) was used to analyze the voltammetric curves and to evaluate the capability of the discrimination of the array of sensors. The voltammetric curves were mathematically preprocessed. After normalization a windowed slicing method was used to reduce the number of data per sample (Parra et al., 2004). Using this method, 10 parameters per curve were obtained and used as a data source for statistical analysis. All computations and chemometric analysis were carried out using the software Matlab v5.3.

\section{Results and discussion}

\subsection{Langmuir monolayers and Langmuir-Blodgett films}

The isotherm of $\mathrm{AA} / \mathrm{LuPc}_{2}$ registered in $\mathrm{PBS}-\mathrm{NaCl}$ subphase is shown in Fig. 1a. The limiting area calculated from the slope of the curve was $37 \AA^{2}$. This value corresponds to an edge-on orientation with the Pc ring tilted and assembled with the main molecular axis parallel to the water subphase (lying flat they should occupy an area approximately $20 \AA \times 20 \AA$ ) (Casili et al., 2005).

Tyrosinase and laccase could be effectively adsorbed into the non-compressed $\mathrm{AA} / \mathrm{LuPc}_{2}$ films as demonstrated by the increase in the surface pressure that occurred upon injection of the enzymes underneath the air/liquid interface. In the case of tyrosinase, a constant and progressive increase in the surface pressure was observed. After $45 \mathrm{~min}$ (when the surface pressure reached a value of ca. $0.35 \mathrm{mN} \mathrm{m}^{-1}$ ) a plateau was attained. The changes in pressure due to the incorporation of the laccase to the non-compressed film followed a different kinetics. The increase in the surface pressure started $30 \mathrm{~min}$ after the injection and reached a plateau $30 \mathrm{~min}$ later at $0.40 \mathrm{mN} \mathrm{m}^{-1}$ (total time for saturation was $60 \mathrm{~min}$ ).

Once the surface pressure was stabilized, the floating films were compressed at a constant speed of $10 \mathrm{~mm} \mathrm{~min}^{-1}$. Under these conditions reproducible isotherms were obtained (Fig. 1a).

The shapes of these isotherms differ from that of $\mathrm{AA} / \mathrm{LuPc}_{2}$. The formation of the bidimensional solids started at higher areas per molecule and the limiting areas per molecule were larger than the values observed for the $\mathrm{AA} / \mathrm{LuPc}_{2}$ Langmuir film, confirming the adsorption of the enzymes into the films. The different areas per molecule observed for $\operatorname{Tyr} / \mathrm{AA} / \mathrm{LuPc}_{2}\left(51 \mathrm{mN} \mathrm{m}{ }^{-1}\right)$ and Lac/AA/ $\mathrm{LuPc}_{2}\left(47 \mathrm{mN} \mathrm{m}^{-1}\right)$, can be attributed to the different size and molecular weight of both enzymes ( $120 \mathrm{kDa}$ for tyrosinase and 50-100 kDa for laccase).

The adsorption of the enzyme into the floating films was also confirmed by the dependence of the limiting area with the time elapsed between the injection of the enzyme and the beginning of the compression. This is also illustrated in Fig. 1a, where isotherms registered by waiting 30 and $60 \mathrm{~min}$ between the injection of the enzyme and the beginning of the compression are compared. In the case of Tyr/AA/LuPc 2 , the limiting area increased with the time elapsed after injection (from 0 to $30 \mathrm{~min}$ ), but isotherms registered after waiting 30 or 60 min were almost identical. The variation was dramatic for the $\mathrm{Lac} / \mathrm{AA} / \mathrm{LuPc}_{2}$. This result is in good accordance with the different adsorption kinetics mentioned in the previous paragraphs.

Compression-expansion cycles were also studied. Upon decompression, $\mathrm{AA} / \mathrm{LuPc}_{2}$ floating monolayers showed a certain hysteresis, but successive compression-expansion cycles where highly reproducible (Fig. 1b). Hysteresis was also observed in monolayers containing tyrosinase (Fig. 1c) or laccase (Fig. 1d). The isotherms of the decompression were similar to those of $\mathrm{AA} / \mathrm{LuPc}_{2}$ film,

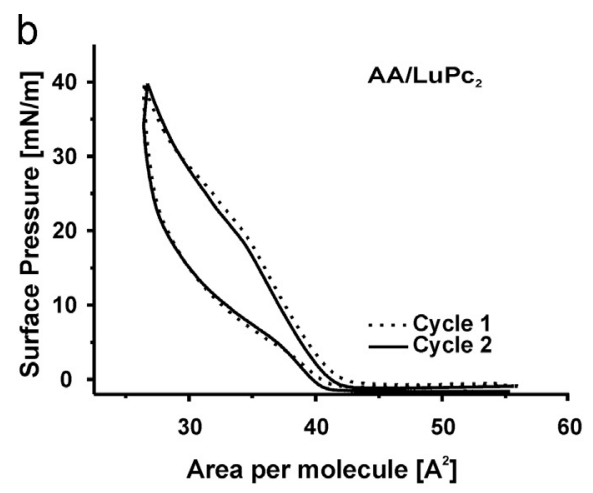

d

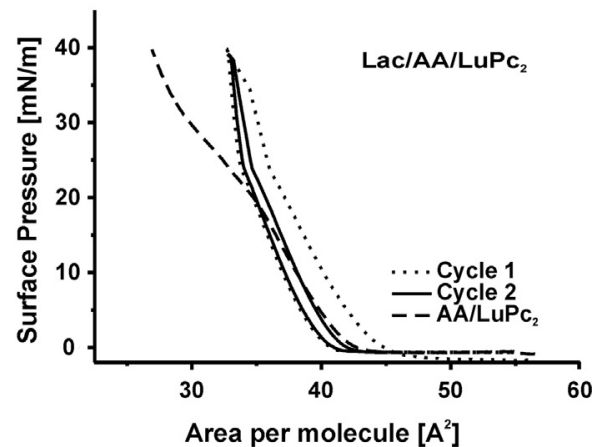

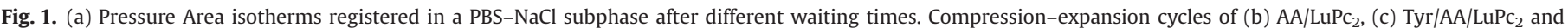
(d) $\mathrm{Lac} / \mathrm{AA} / \mathrm{LuPc}_{2}$. 
pointing to the desorption of the enzyme during the expansion cycle. During the second cycle, the Tyr/AA/LuPc $c_{2}$ film recovered the original shape, but the second compression of $\mathrm{Lac} / \mathrm{AA} / \mathrm{LuPc}_{2}$ was similar to the isotherm of the $\mathrm{AA} / \mathrm{LuPc}_{2}$ film. This means that after desorption, tyrosinase could be partially reinserted, whereas laccase could not be readsorbed into the film. It can be concluded that the insertion of laccase into the floating film is more difficult than the insertion of tyrosinase. This could seem surprising because the size of tyrosinase is considerably larger than that of laccase. However, the hydrophobic environment provided by the floating film is more favorable for the tyrosinase which is a transmembrane protein and only a small part of the enzyme extends in the cytoplasmic hydrophilic environment.

The quality of the floating films was further analyzed with Brewster Angle Microscopy (BAM). The homogeneity of the Langmuir films containing tyrosinase or laccase was similar to that of the $\mathrm{AA} / \mathrm{LuPc}_{2}$ films (Fig. 2).

In order to visualize the topography of the LB films AFM was employed. As presented in Fig. 2, AA/LuPc 2 films showed a homogeneous and smooth surface. In Enz/AA/LuPc 2 films, immobilized enzymes were clearly observed showing their characteristic cloud-like morphology. The enzymes were well and evenly distributed on the surface of the electrode, and no large aggregates were formed. A scheme of the structure of the electrodes has been inserted in the figure.

\subsection{Electrochemical response towards phenols}

The voltammetric responses of the array formed by three electrodes $\left(\mathrm{AA} / \mathrm{LuPc}_{2}, \mathrm{Tyr} / \mathrm{AA} / \mathrm{LuPc}_{2}\right.$ and $\left.\mathrm{Lac} / \mathrm{AA} / \mathrm{LuPc}_{2}\right)$ towards six phenolic compounds $\left(40 \mu \mathrm{mol} \mathrm{L}^{-1}\right)$ are shown in Fig. 3. The responses were highly reproducible with a coefficient of variation $(n=10)$ lower than $1.5 \%$ (calculated from the peaks associated with antioxidants) and lower than $0.75 \%$ (calculated from the peaks associated with $\mathrm{LuPc}_{2}$ ). The reproducibility between different sensors, containing the same enzyme, immersed in the same solution was always lower than $1.75 \%$.

The electrochemical response of $\mathrm{AA} / \mathrm{LuPc}_{2}$ nanostructured films towards phenols (represented in Fig. 3 as dashed lines) showed a quasi-reversible and intense redox pair associated with the $\operatorname{LuPc}_{2}^{-} / \mathrm{LuPC}_{2}^{0}$ process at ca. $\mathrm{E}_{1 / 2=}-0.15 \mathrm{~V}$. However, due to the interaction with phenols, this peak appeared at different positions and showed diverse intensities depending on the antioxidant analyzed. Voltammograms also showed redox processes arising from the oxidation/reduction of phenols. The position and intensity of such peaks depended on the type of phenol and were in good accordance with previously published results (Apetrei et al., 2011; Makhotina and Kilmartin, 2010).

Taking into account that the oxidation of phenols does not take place at bare ITO electrodes and considering that when using a carbon paste electrode the oxidation occurs at higher potentials than those reported here (Makhotina and Kilmartin, 2010), it can be confirmed that the $\mathrm{AA} / \mathrm{LuPc}_{2}$ sensor reduces the overpotential and improves the reversibility, validating the electrocatalytic behavior of the $\mathrm{LuPc}_{2}$. For instance, the oxidation of catechol in carbon paste electrode occurred at $0.5 \mathrm{~V}$ and the reduction in the reverse scan appear at $0.05 \mathrm{~V}\left(\Delta E_{1 / 2}=0.45 \mathrm{~V}\right)$. When using a $\mathrm{AA} /$ $\mathrm{LuPc}_{2}$ sensor, the oxidation of the phenol appear at $0.4 \mathrm{~V}$ and the cathodic wave at $0.15 \mathrm{~V}(\Delta E=0.25 \mathrm{~V})$. The intensity of the peaks was also clearly increased.

One of the objectives of this work was to improve the selectivity of the sensors by introducing enzymes in biomimetic layers containing $\mathrm{LuPc}_{2}$ as electron mediator (Apetrei et al., 2011; Pavinatto et al., 2011; Yin et al., 2009). Two phenoloxidases (tyrosinase and laccase) were selected. Tyrosinase oxidizes monophenols and o-diphenols to the corresponding quinone, whereas laccase catalyzes the oxidation of a larger variety of aromatic compounds such as substituted monoand polyphenols (Cortina-Puig et al., 2011).

Using this strategy, $\mathrm{Tyr} / \mathrm{AA} / \mathrm{LuPc}_{2}$ and $\mathrm{Lac} / \mathrm{AA} / \mathrm{LuPc}_{2}$ sensors were prepared and their response towards phenols was analyzed
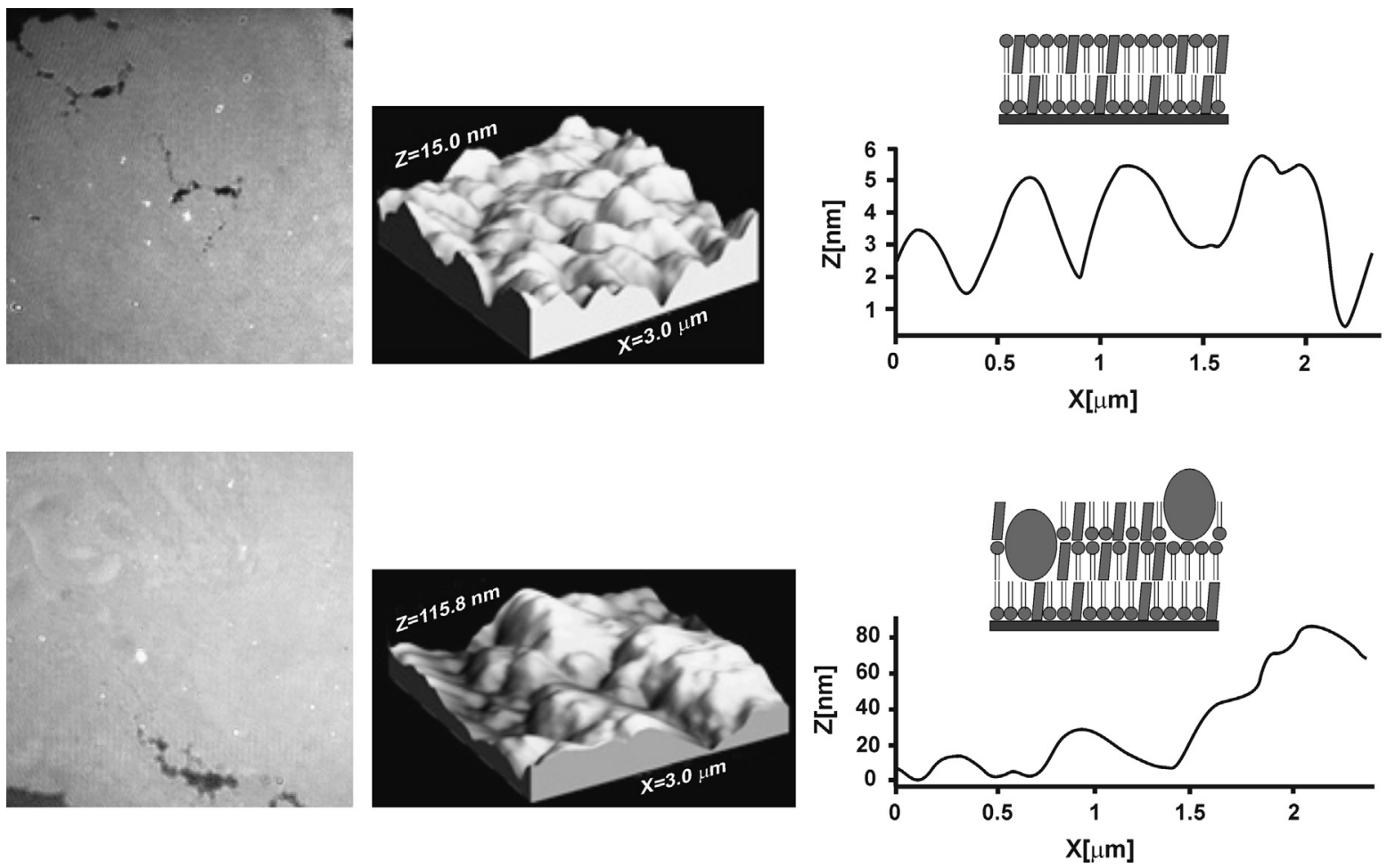

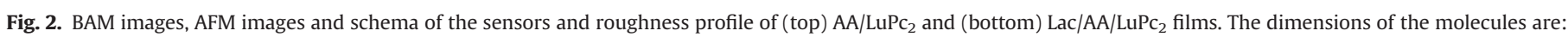
AA ca. $15 \times 30 \AA^{2}, \square \operatorname{LuPc}_{2}$ ca. $20 \times 20 \AA^{2}$, (laccase ca. $55 \times 55 \times 45 \AA^{3}$ (according to Piontek et al., 2002). 

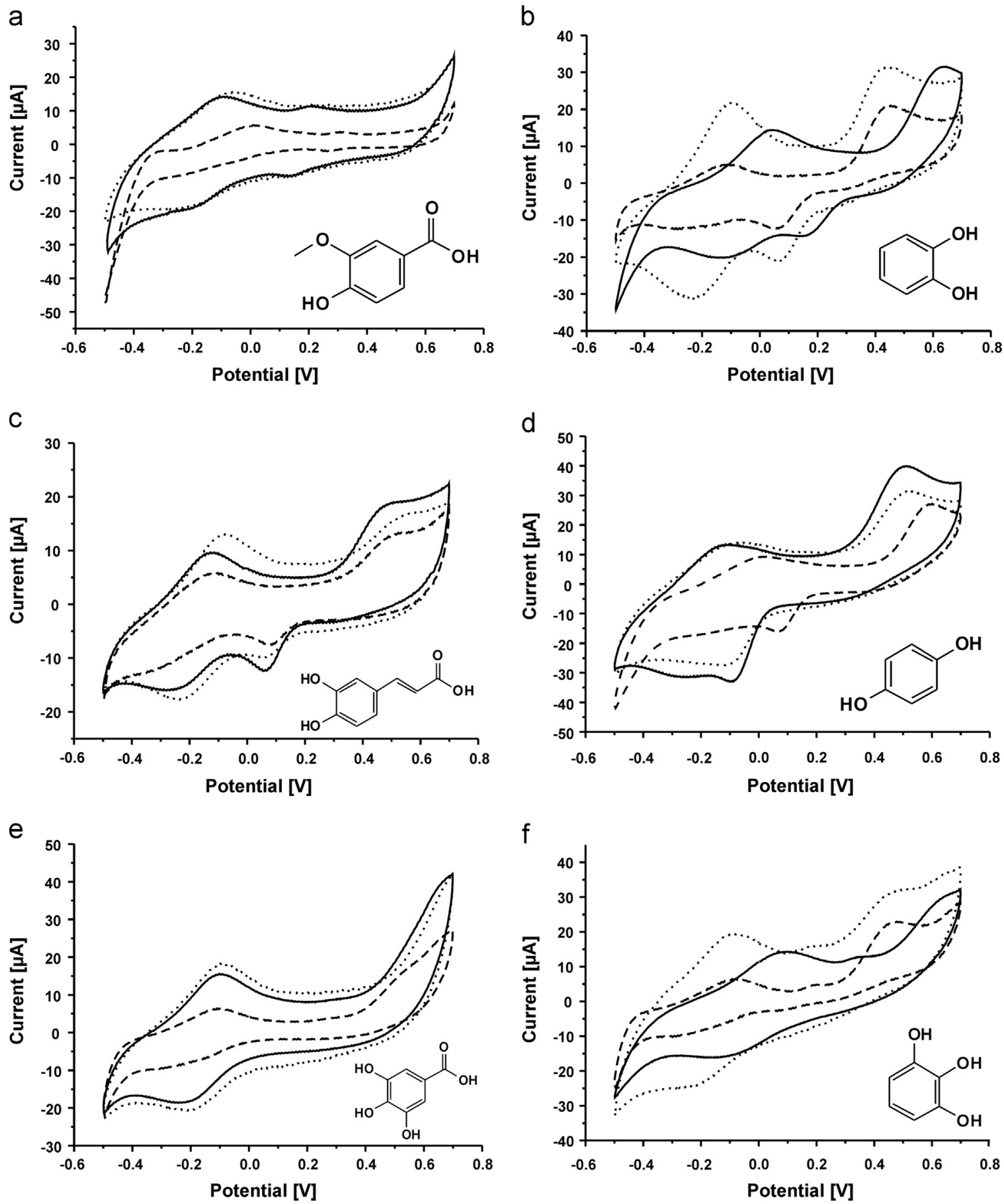

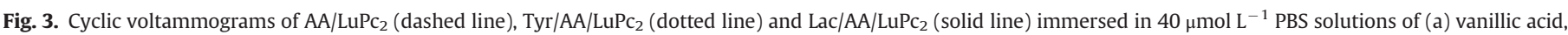
(b) catechol, (c) caffeic acid, (d) hydroquinone, (e) gallic acid and (f) pyrogallol.

in terms of sensitivity and cross-selectivity. The results are shown in Fig. 3 (Tyr/AA/LuPc 2 responses are represented as dotted lines and $\mathrm{Lac} / \mathrm{AA} / \mathrm{LuPc}_{2}$ as solid lines). When biosensors containing tyrosinase or laccase are immersed in a phenolic solution, the phenol is enzymatically oxidized to the corresponding quinone (no need of external voltage). When the voltage was biased to positive values, an anodic peak at ca. $0.5 \mathrm{~V}$ was observed. This peak corresponded to the electrochemical oxidation of the phenol to the quinoid form. During the reverse scan, both the enzymatically and the electrochemically formed o-quinone molecules were reduced simultaneously at ca. $-0.2 \mathrm{~V}$. This concurrent reduction explains why this peak was more intense in $\mathrm{Enz} / \mathrm{AA} / \mathrm{LuPc}_{2}$ than in $\mathrm{AA} / \mathrm{LuPc}_{2}$ sensors. Moreover, the enzymatic processes were favored by the presence of the $\mathrm{LuPc}_{2}$, which acted as electron mediator, producing signal amplification.

Unexpectedly, the presence of the enzyme also increased the intensity of the peaks associated with the oxidation/reduction of the phthalocyanine ring (at ca. $-0.2 \mathrm{~V}$ ). These changes confirmed the interaction between the phthalocyanine and the enzyme and the subsequent electrocatalytic effect.

The most remarkable conclusion that can be extracted from Fig. 3 is the important degree of cross-selectivity attained by the 
array of sensors. Significant differences were observed in the responses of Tyr/AA/LuPc $c_{2}$ and $\mathrm{Lac} / \mathrm{Tyr} / \mathrm{LuPc}_{2}$ that come from their different specificity.

For instance, as both enzymes react with monophenols, their response towards vanillic acid was similar. Catechol is an odiphenol and consequently the response shown by the tyrosinase was clearly more intense than the response observed in laccase. Moreover, the electrochemical oxidation of catechol occurred at lower potentials in $\mathrm{Tyr} / \mathrm{AA} / \mathrm{LuPc}_{2}(0.38 \mathrm{~V})$ than in $\mathrm{Lac} / \mathrm{AA} / \mathrm{LuPc}_{2}$ $(0.62 \mathrm{~V})$. Caffeic acid is also an o-diphenol, but the presence of substituents in the benzene ring changes the polarity and the size of the substrate, modifying the interaction with the active site of the tyrosinase. A similar argument applies for hydroquinone, a p-diphenol, which shows higher affinity towards laccase.

The triphenols tested, gallic acid and pyrogallol, showed completely different responses towards $\mathrm{Tyr} / \mathrm{AA} / \mathrm{LuPc}_{2}$ and $\mathrm{Lac} / \mathrm{AA} / \mathrm{LuPc}_{2}$. Gallic acid is a substituted triphenol and according to the results obtained, its affinity towards tyrosinase and laccase is not good because enzymatic activity was not observed. In the case of pyrogallol, the first cycle was clearly different from the signals obtained in the subsequent ones which were reproducible and similar to those obtained when the electrodes were immersed in catechol. The reason is that the oxidation of pyrogallol occurs in two steps: during the first cycle, the quinoid form is obtained and during the second cycle, the redox properties of the o-quinone are observed. This behavior also explains that sensors modified with tyrosinase or laccase provided different responses, due to their different affinity towards o-diphenols.

The detection limits were determined by measuring the responses of the sensors towards phenol solutions with concentrations ranging from 4 to $150 \mu \mathrm{mol} \mathrm{L}^{-1}$. The peaks associated with phenols were clearly identified by the progressive increase in their intensity. The intensity of such peaks increased linearly with the antioxidant concentration. The detection limits were statistically calculated using $\mathrm{DL}=3 . \mathrm{SB} / b$, where $\mathrm{SB}$ is the standard deviation of the blank at the potential measured and $b$ is the slope of the calibration curve. Peak positions, detection limits and regression coefficients are shown in Table 1 . All the curves and calibration graphs have been included as supporting material.

Table 1

Detection limits calculated from the peak potentials associated with phenols.

\begin{tabular}{|c|c|c|c|c|c|c|}
\hline Sensor & $E_{\mathrm{a}}[\mathbf{V}]$ & LD $\left[\mathrm{mol} \mathrm{L}^{-1]}\right.$ & $R^{2}$ & $E_{\mathrm{c}}[\mathbf{V}]$ & LD $\left(\mathrm{mol} \mathrm{L}^{-1}\right)$ & $R^{2}$ \\
\hline \multicolumn{7}{|l|}{ Vanillic acid } \\
\hline $\mathrm{AA} / \mathrm{LuPc}_{2}$ & 0.200 & $1.33 \times 10^{-4}$ & 0.9209 & 0.100 & $6.59 \times 10^{-5}$ & 0.9208 \\
\hline $\mathrm{Lac} / \mathrm{AA} / \mathrm{LuPc}_{2}$ & 0.200 & $5.10 \times 10^{-6}$ & 0.9747 & 0.110 & $4.06 \times 10^{-6}$ & 0.9764 \\
\hline Tyr/AA/LuPc 2 & 0.200 & $7.69 \times 10^{-6}$ & 0.9619 & 0.100 & $5.45 \times 10^{-6}$ & 0.9753 \\
\hline \multicolumn{7}{|l|}{ Catechol } \\
\hline $\mathrm{AA} / \mathrm{LuPc}_{2}$ & 0.528 & $4.28 \times 10^{-6}$ & 0.9922 & 0.083 & $3.04 \times 10^{-6}$ & 0.9937 \\
\hline $\mathrm{Lac} / \mathrm{AA} / \mathrm{LuPc}_{2}$ & 0.550 & $4.59 \times 10^{-7}$ & 0.9899 & 0.065 & $4.88 \times 10^{-7}$ & 0.9917 \\
\hline Tyr/AA/LuPc 2 & 0.600 & $4.81 \times 10^{-7}$ & 0.9917 & 0.060 & $5.18 \times 10^{-7}$ & 0.9974 \\
\hline \multicolumn{7}{|l|}{ Caffeic acid } \\
\hline $\mathrm{AA} / \mathrm{LuPc}_{2}$ & 0.450 & $4.19 \times 10^{-6}$ & 0.9966 & 0.100 & $3.45 \times 10^{-6}$ & 0.9966 \\
\hline $\mathrm{Lac} / \mathrm{AA} / \mathrm{LuPc}_{2}$ & 0.520 & $5.89 \times 10^{-7}$ & 0.9902 & 0.054 & $7.74 \times 10^{-7}$ & 0.9809 \\
\hline Tyr/AA/LuPc 2 & 0.500 & $5.73 \times 10^{-7}$ & 0.9972 & 0.060 & $6.23 \times 10^{-7}$ & 0.9964 \\
\hline \multicolumn{7}{|c|}{ Hydroquinone } \\
\hline $\mathrm{AA} / \mathrm{LuPc}_{2}$ & 0.600 & $3.34 \times 10^{-6}$ & 0.9882 & 0.058 & $3.38 \times 10^{-6}$ & 0.9892 \\
\hline $\mathrm{Lac} / \mathrm{AA} / \mathrm{LuPc}_{2}$ & 0.550 & $5.18 \times 10^{-7}$ & 0.9764 & -0.090 & $5.42 \times 10^{-6}$ & 0.9718 \\
\hline Tyr/AA/LuPc 2 & 0.600 & $5.94 \times 10^{-7}$ & 0.9955 & -0.100 & $6.40 \times 10^{-7}$ & 0.9948 \\
\hline \multicolumn{7}{|l|}{ Gallic acid } \\
\hline $\mathrm{AA} / \mathrm{LuPc}_{2}$ & 0.698 & $3.69 \times 10^{-6}$ & 0.9922 & & & \\
\hline $\mathrm{Lac} / \mathrm{AA} / \mathrm{LuPc}_{2}$ & 0.699 & $4.10 \times 10^{-8}$ & 0.9905 & & & \\
\hline Tyr/AA/LuPc 2 & 0.700 & $4.97 \times 10^{-7}$ & 0.9851 & & & \\
\hline \multicolumn{7}{|l|}{ Pyrogallol } \\
\hline $\mathrm{AA} / \mathrm{LuPC}_{2}$ & 0.250 & $2.66 \times 10^{-5}$ & 0.9906 & 0.528 & $2.14 \times 10^{-6}$ & 0.9886 \\
\hline $\mathrm{Lac} / \mathrm{AA} / \mathrm{LuPc}_{2}$ & 0.360 & $1.87 \times 10^{-6}$ & 0.9979 & 0.699 & $3.05 \times 10^{-7}$ & 0.9980 \\
\hline $\mathrm{Tyr} / \mathrm{AA} / \mathrm{LuPc}_{2}$ & 0.200 & $3.41 \times 10^{-6}$ & 0.9925 & 0.500 & $4.51 \times 10^{-7}$ & 0.9921 \\
\hline
\end{tabular}

The detection limits found in $\mathrm{Enz} / \mathrm{AA} / \mathrm{LuPc}_{2}$ were at least one order of magnitude lower than those found in $\mathrm{AA} / \mathrm{LuPc}_{2}$. They were in the range of those published for tyrosinase biosensors containing other electron mediators (Tang et al., 2013).

The dynamic behavior was examined by analyzing the effect of the sweep rate (from 0.025 to $0.2 \mathrm{~V} \mathrm{~s}^{-1}$ ) on the intensity of the voltammetric responses. The experiments were carried out in $100 \mu \mathrm{mol} \mathrm{L}^{-1}$ phenolic solutions. A clear dependence of the intensity of the peaks with the square root of the sweep rate could be noticed for all the phenols and sensors analyzed (Fig. 4). It is worthily noting that in the case of the Enz/AA/LuPc 2 films, the linear relationship between the peak current and the square root of the scan rate was approximately 5 times faster than the value found in the $\mathrm{AA} / \mathrm{LuPc}_{2}$ electrode. This result indicates that the charge transfer within the LB film and/or through the electrode interface is facilitated and this improvement should be related with the enzymatic activity.

\subsection{Array of sensors: response towards phenolic compounds}

The intrinsic complexity and cross-selectivity of the signals generated by the array of voltammetric electrodes could be used to discriminate the phenols using Principal Component Analysis (PCA). The high amount of information displayed by the voltammograms, makes difficult the data analysis, increasing the processing time. A pre-treatment method of the voltammetric curves has been developed in our laboratory that allows reducing the number of variables to a few representative values (Parra et al., 2004, 2006). As a result of the calculations, 10 input variables were

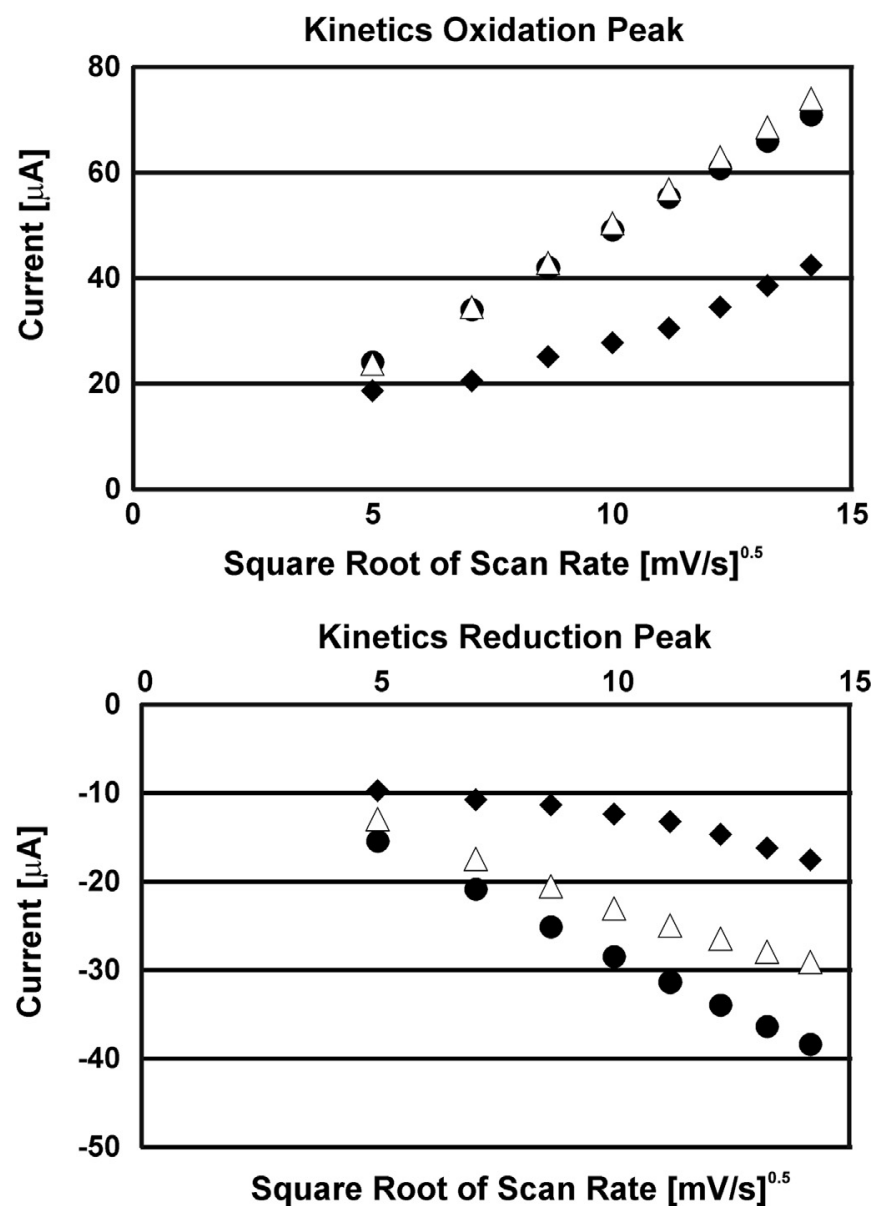

Fig. 4. Relationship between the intensity of (top) anodic and (bottom) cathodic peaks vs. the square root of the scan rate $\left(\nu^{1 / 2}\right): \triangle \mathrm{AA} / \mathrm{LuPc}_{2} ;(\bullet) \mathrm{Tyr} / \mathrm{AA} / \mathrm{LuPc}_{2} ;(\bullet)$ $\mathrm{Lac} / \mathrm{AA} / \mathrm{LuPc}_{2}$, immersed in caffeic acid $100 \mu \mathrm{mol.L}{ }^{-1}$. 
a

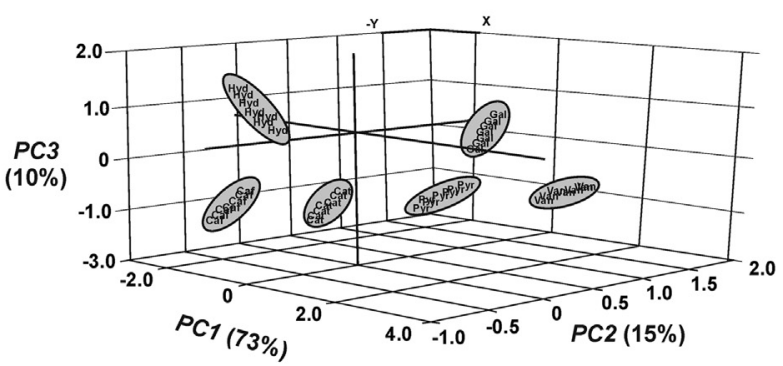

C

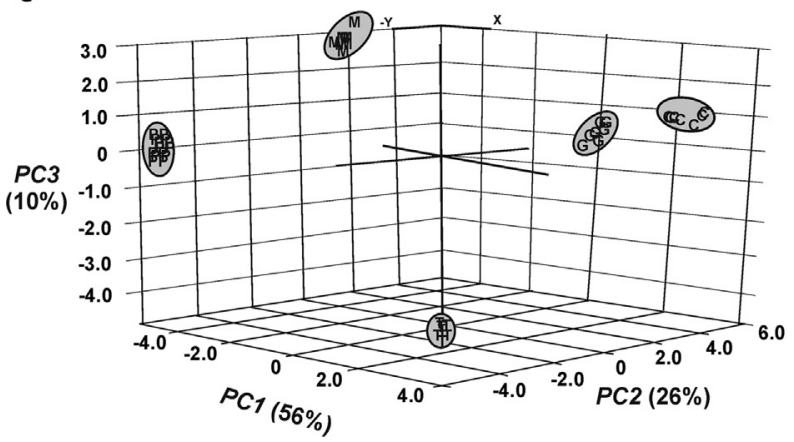

b

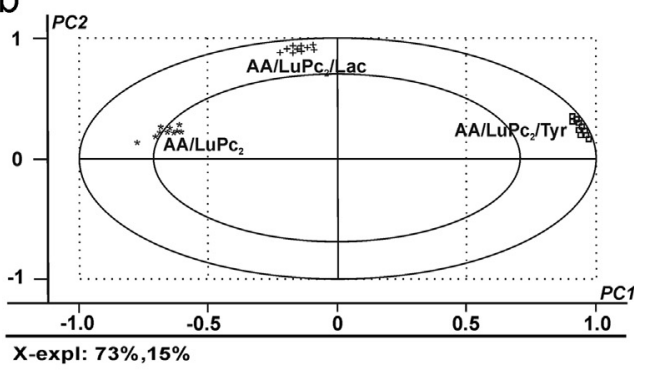

d

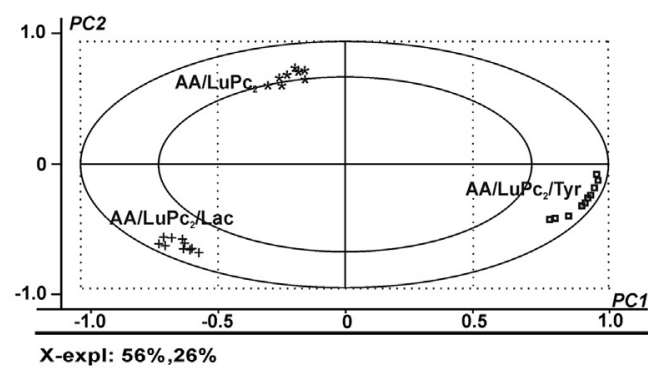

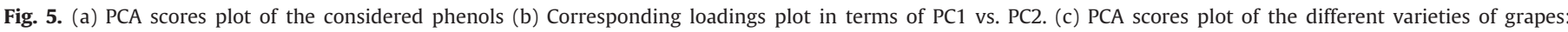
T-Tempranillo, G-Garnacha, C-Cabernet, M-Mencia, PP-Prieto Picudo. (d) Corresponding loadings plot in terms of PC1 vs. PC2.

extracted for each voltammetric curve and used for PCA calculations. As shown in the PCA scores plot (Fig. 5a) PC1, PC2 and PC3 explained $98 \%$ of the total variance between the samples. The separated clusters indicated that the six phenols could be clearly discriminated. The graph could be divided into three regions corresponding to the chemical structure of the studied phenols: the monophenol (vanillic acid) appeared in the region of positive PC1. The three diphenols (catechol, caffeic acid and hydroquinone) appeared in the left part of the graph in the negative PC1 region. Finally, gallic acid and pyrogalloll (triphenols) were located in the middle region of PC1 and PC2 but in positive PC3 values.

Fig. 5b shows the contribution of the variables (10 kernels per sensor) in a two-dimensional PCA loading plot. As observed in the figure, all the variables used in the PCA analysis showed high loading parameters for a particular principal component, indicating a positive influence in the discrimination process. Moreover, Fig. 5b shows that the variables associated to each sensor appear in different regions of the plot.

\subsection{Array of sensors: response towards grapes}

The array of sensors and biosensors described in the previous sections was exposed to musts prepared from grapes of different varieties (diluted $50 \%$ in water). Voltammograms were dominated by the redox response of the phenolic groups present in musts that appeared as anodic peaks in the $0.4-0.8 \mathrm{~V}$ region, and the corresponding cathodic waves in the $0.35 \mathrm{~V}$ region. The intensities and positions of those peaks were related with the total polyphenols index measured by chemical methods, that in turn depended on the grape variety. The responses were highly reproducible with a coefficient of variation $(n=7)$ always lower than $4.5 \%$. Obviously in such a complex media, the peaks were broader than in the phenolic solutions and a variety of other small and not well-defined peaks were observed. In summary, each electrode provided a different response towards the same must sample and an important degree of cross-selectivity was attained.
As observed in the PCA scores plot, the array was able to discriminate grapes according to the grape variety (Fig. 5c). PC1, PC2 and PC3 explained 92\% of the total variance between musts. The position of the clusters were related with the chemical composition of the grape juices. The third Principal Component PC3, was the responsible of the discrimination of the samples according to their Total Polyphenol Index: The must obtained from the variety Mencia (TPI of 12) appeared in the top part of the graph in the PC3 positive values, whereas the must obtained from Tempranillo (TPI of 20) was located in the lower part of the figure. Musts obtained from Garnacha, Cabernet an Prieto Picudo grapes which have an intermediate TPI value (TPI of 15) appeared in the middle region. Also in the case of musts, the loading plot confirmed the complementarity of the sensors forming the array (Fig. 5d).

\section{Conclusions}

A bioelectronic tongue formed by three sensors based on Langmuir-Blodgett films of arachidic acid containing tyrosinase or laccase and using lutetium bisphthalocyanine as an electron mediator has been constructed. The increase in the area per molecule observed in the surface pressure-area isotherms and the AFM images indicate that enzymes are imbibed inside the floating monolayer formed by $\mathrm{LuPc}_{2}$ and $\mathrm{AA}$ with different kinetics. The hydrophobic environment provided by the floating film is more favorable for the tyrosinase which is a transmembrane protein.

The electrochemical responses of the sensors towards phenolic compounds (mono, di and triphenols) depend on the nature of the enzymes and on their different enzymatic specificity. The biomimetic environment improves the dynamic behavior and the detection limits which are in the range of $10^{-7}-10^{-8} \mathrm{~mol} \mathrm{~L}{ }^{-1}$.

The bioelectronic tongue is able to discriminate phenols according to the chemical nature of the phenolic molecules. In addition, the system is able to discriminate musts according to 
their Total Polyphenolic Index. The loading plots confirm the excellent complementarity of the sensors forming the array.

It has been demonstrated that the proposed array of sensors combines the advantages of classical phthalocyanine basedsensors that provide global information about the sample, with the specificity of the enzyme-substrate reaction typical of biosensors. For this reason, the selectivity of the multisensor system and its capability of discrimination are clearly improved when biosensors containing tyrosinase and laccase are included in the array.

The high functionality of the enzyme obtained using a biomimetic immobilization method, the selectivity afforded by enzyme catalysis and the signal enhancement caused by the lutetium bisphthalocyanine mediator make this bioelectronics tongue attractive for the analysis of grapes.

\section{Acknowledgments}

Financial support by the MINECO (grant CICYT-AGL201233535) and Junta Castilla y León (VA-032U13) is gratefully acknowledged. CMP also thanks the University of Valladolid for the fellowship (PIF-UVa). ISOM is acknowledged for the AFM measures.

\section{Appendix A. Supplementary material}

Supplementary data associated with this article can be found in the online version at http://dx.doi.org/10.1016/j.bios.2014.02.023.

\section{References}

Apetrei, C., Alessio, P., Constantino, C.J.L., De Saja, J.A., Rodriguez-Mendez, M.L., Pavinatto, F.J., Fernandes, E.G., Zucolotto, V., Oliveira , O.N., 2011. Biosens. Bioelectron. 26, 2513-2519.

Arrieta, A., Rodriguez-Mendez, M.L., de Saja, J.A., 2003. Sens. Actuators B-Chem. 95 $357-365$.

Bartosz, G., 2013. Food oxidants and antioxidants: chemical, biological, and functional properties (chemical and functional properties of food components). CRC press, Florida.

Bouvet, M., Gaudillat, P., Suisse, J.M., 2013. J. Porph. Phthaloc. 17, 913-919.

Cabral, F.P.A., Bergamo, B.B., Dantas, C.A.R., Riul, A., Giacometti, J.A., 2009. Rev. Sci. Instrum. 80, 026107-026107-3.

Casili, S., De Luca, M.A., Apetrei, C., Parra, V., Arrieta, A., Valli, L., Jiang, J., RodríguezMéndez, M.L., de Saja, J.A., 2005. App. Surf. Sci. 246, 304-313.
Ceto, X., Gutierrez, J.M., Gutierrez, M., Céspedes, F., Capdevila, J., Mínguez, S., Jimenez-Jorquera, C., del Valle, M., 2012a. Anal. Chim. Acta. 732, 172-179.

Ceto, X., Cespedes, F., Pividori, M.I., Gutierrez, J.M., del Valle, M., 2012b. Analyst 137, 349-356.

Ciosek, P., Wroblewski, W., 2011. Sensors 11, 4688-4701.

Cortina-Puig, M., Noguer, T., Marty, J.L., Calas-Blanchard, C., 2011. In: Mehmet Mutlu (Ed.), In Biosensors in Food processing, safety and quality control. CRC Press, Boca Raton, London, NY, pp. 257-272

Escobar, J.D., Alcaniz, M., Masot, R., Fuentes, A., Bataller, R., Soto, J., Barat, J.M., 2013. Food Chem. 138, 814-820.

Fernandes, E.G.R., Brazaca, L.C., Rodriguez-Mendez, M.L., de Saja, J.A., Zucolotto, V., 2011. Biosens. Bioelectron. 26, 4715-4719.

Gay, M., Muñoz, R., De Saja, J.A., Rodriguez-Mendez, M.L., 2012. Electrochim. Acta. $68,88-94$.

Ghasemi-Varnamkhasti, M., Rodriguez-Mendez, M.L., Mohtasebi, S.S., Apetrei, C., Lozano, J., Ahmadi, H., Razavi, S.H., de Saja, J.A., 2012. Food Control. 25, 216-224.

Karim, F., Fakhruddin, A.N. M., 2012. Rev. Environ. Sci. Biotechnol. 11, 261-274.

Linaje, M., Quintanilla, M.C., Gonzalez, A., del Valle, J.L., Alcaide, G., RodriguezMendez, M.L., 2000. Analyst 125, 341-346.

Makhotina, O., Kilmartin, P.A., 2010. Anal. Chim. Acta. 668, 155-165.

Matemadombo, F., Apetrei, C., Nyokong, T., Rodriguez-Mendez, M.L., de Saja, J.A., 2012. Sens. Actuators B-Chem. 457, 166-167.

Mello, L.D., Del Río, D., Costa, L.G., Lean, M.E.J., Crozier, A., 2010. Nutr. Metab. Cardiovasc. Dis. 20, 1-6.

OIV,. 2013, Compendium of International Methods of Analysis of Wines and Musts, 2.

Parra, V., Hernando, T., Rodríguez-Méndez, M.L., de Saja, J.A., 2004. Electrochim. Acta. 49, 5177-5185.

Parra, V., Arrieta, A., Fernández-Escudero, J.A., García, H., Apetrei, C., RodriguezMendez, M.L., de Saja, J.A., 2006. Sens. Actuators B 115, 54-61.

Pavinatto, F.J., Fernandez, E.G.R., Alessio, P., Constantino, C.J.L., de Saja, J.A., Zucolotto, V., Oliveira, O.N.Jr, Apetrei, C., Rodriguez-Mendez, M.L, 2011. J. Mater. Chem. 21, 4995-5003.

Piontek, K., Antorini, M., Choinowski, T., 2002. J. Biol. Chem. 277, 37663-37669.

Rodriguez-Mendez, M.L., Parra, V., Apetrei, C., Gay, M., Prieto, N., de Saja, J.A., 2008. Microchim. Acta. 163, 23-31.

Scampicchio, M., Ballabio, D., Arecchi, A., Cosio, S.M., Mannino, S., 2008. Electrochim. Acta. 163, 11-21.

Soloducho, J., Cabaj, J., Swist, A., 2009. Sensors 9, 7733-7752.

Tahara, Y., Toko, K., 2013. IEEE Sens. J. 13, 3001-3011.

Tang, L., Zhou, Y.Y., Zeng, G.M., Li, Z., Liu, Y.Y., Zhang, Y., Chen, G.Q., Yang, G.D., Lei, X.X., Wu, M.S., 2013. Analyst 138, 3552-3560.

Vlasov, Y., Legin, A., Rudnitskaya, A., Di Natale, C., D’Amico, A., 2005. Pure Appl. Chem. 77, 1965-1983.

Volpati, D., Alessio, P., Zanfolim, A.A., Storti, F.C., Job, A.E., Ferreira, M., Riul, A., Oliveira Jr., O.N., Constantino, C.J.L., 2008. J. Phys. Chem. B 112, 15275-15282.

Winquist, F., Olsson, J., Eriksson, M., 2011. Anal. Chim. Acta. 10, 192-197.

Yin, H.S., Zhou, Y.L., Ai, S.Y., 2009. J. Electroanal. Chem. 626, 80-88.

Yin, H.S., Zhou, Y.L., Xu, J., Ai, S.Y., Cui, L., Zhu, L.S., 2010. Anal. Chim. Acta. 659, 144-150.

Zagal, J.H., Griveau, S., Silva, J.F., Nyokong, T., Bedioui, F., 2010. Coord. Chem. Rev. $254,2755-2794$. 